J Allergy Clin Immunol Pract. 2020 October ; 8(9): 3029-3035.e4. doi:10.1016/j.jaip.2020.05.022.

\title{
Elevated testosterone is associated with decreased likelihood of current asthma regardless of sex
}

\author{
Adeeb B. Bulkhi, MD ${ }^{1,2}$, Kirk V. Shepard II, MD1, Thomas B. Casale, MD¹, Juan Carlos \\ Cardet, MD, MPH ${ }^{1}$ \\ ${ }^{1}$ Division of Allergy and Immunology, Department of Internal Medicine, University of South \\ Florida, Morsani College of Medicine and James A. Haley Veterans' Hospital, Tampa, FL, USA. \\ ${ }^{2}$ Department of Internal Medicine, College of Medicine, Umm Al Qura University, Makkah, Saudi \\ Arabia.
}

\section{Abstract}

Background: Asthma prevalence decreases post-puberty in males. Testosterone inhibits airway smooth muscle contraction and attenuates type 2 inflammation.

Objective: To investigate the relationship between serum testosterone and current asthma prevalence and lung function in a nationally-representative dataset.

Methods: Serum testosterone and self-reported physician-diagnosed current asthma were obtained from 7,584 participants ages 6-80 years from the cross-sectional 2011-2012 National Health and Nutrition Examination Survey (NHANES). We used logistic regression to test associations between testosterone and current asthma, adjusting for demographics and stratifying by sex and age; linear regression to evaluate correlations between testosterone and lung function among asthmatic patients; and interaction terms to test for effect modification by blood eosinophils and FeNO.

Results: Serum testosterone inversely associated with odds of current asthma in both men and women but this association was nonlinear. Similar protective effect sizes were observed for both sexes after $\log _{2}$-transformation of serum testosterone. For every 1-unit increase in $\log _{2}$ testosterone, the odds of current asthma decreased by $11 \%$ in men and $10 \%$ in women, although the association was statistically significant in women only among those $\geq 12$ years old after multiple imputation. Serum testosterone did not associate with current asthma prevalence among those $<12$ years old. Testosterone associated with increases in $\mathrm{FEV}_{1}$ in asthmatic participants of

Correspondence: Juan Carlos Cardet, MD, MPH, Division of Allergy and Immunology, Department of Internal Medicine, University of South Florida, Morsani College of Medicine, 12901 Bruce B. Downs Blvd, MDC19, suite 4128, Tampa, FL, 33612-4799, USA., Tel: 813-974-2354, Fax: 813-905-9958, jcardet@ health.usf.edu.

Adeeb B. Bulkhi (co-first author)

Kirk V. Shepard (co-first author)

Publisher's Disclaimer: This is a PDF file of an unedited manuscript that has been accepted for publication. As a service to our customers we are providing this early version of the manuscript. The manuscript will undergo copyediting, typesetting, and review of the resulting proof before it is published in its final form. Please note that during the production process errors may be discovered which could affect the content, and all legal disclaimers that apply to the journal pertain.

Conflict of interest disclosures:

TBC reports that his university employer has received grants and consulting fees from Genentech, Inc., and Novartis. KVS, ABB, and JCC have no conflicts of interest to disclose. 
both sexes. Neither blood eosinophils nor FeNO modified the association between testosterone and current asthma.

Conclusion: Serum testosterone inversely associates with current asthma prevalence regardless of sex and correlates with better lung function in a nationally-representative database. Androgen therapy for asthma should be further investigated.

\section{Keywords}

Asthma; testosterone; androgens; sex disparities; bronchoconstriction; airway smooth muscle; type 2 inflammation; airway obstruction; FeNO

\section{Introduction}

The relationship between sex hormones and asthma is incompletely understood. Epidemiological studies describe sex disparities in asthma which fluctuate throughout life(1-4). During childhood, asthma prevalence and morbidity are higher among males than females $(5,6)$. A reversal occurs during adolescence whereby asthma prevalence and morbidity decrease in males and increase in females(6-10). This sex disparity remains so until menopause(11). Asthma prevalence and morbidity increase again in males after the fifth decade(12), when testosterone levels coincidentally decrease(13). These observations suggest that sex hormones play a pivotal role in asthma pathobiology.

Airway smooth muscle hypertrophy and hyperplasia are cardinal features of asthma, and in vitro and in vivo studies have demonstrated that testosterone attenuates airway smooth muscle hyperplasia and constriction $(14,15)$. Male sex hormones (i.e. androgens) seem to attenuate type 2 airway inflammation, which is present in most asthmatic patients(16-18). These findings suggest that androgens have effects on cellular targets that may attenuate asthmatic pathobiology.

Complementary to in vitro and in vivo data in other species, interventional studies with androgens in humans suggest a potential therapeutic role. Wenzel et al reported improved Asthma Control Questionnaire (ACQ) scores in patients with moderate-to-severe asthma receiving $70 \mathrm{mg}$ of nebulized dehydroepiandrosterone-3-sulfate vs. those receiving placebo (median improvement in ACQ $=-0.72$ vs. -0.43 , respectively)(19). Further, epidemiological data suggest that androgens associate with better lung function in the general population(20), but a similar large-scale epidemiological study among phenotypically characterized asthmatic patients has not been conducted. A recent study also showed that androgens associate with better lung function and symptom control among adolescents with asthma(21), but although it analyzed data from well characterized asthmatic patients, it was not nationally-representative nor did it consider asthma across the ages. Data are lacking on the relationship between serum testosterone, current asthma prevalence, and lung function among asthmatic patients in a large, nationally-representative dataset across the age spectrum. We hypothesized that greater serum testosterone levels would associate with a lower asthma prevalence and better lung function among asthmatic participants, and investigated these associations in regards to markers of type 2 inflammation. 


\section{Methods}

\section{Study design and population}

Cross-sectional data were obtained from the 2011-2012 National Health and Nutrition Examination Survey (NHANES). NHANES consists of voluntary US-based surveys administered every two years to assess non-institutionalized individuals' health through interviews, physical exams, and diagnostic evaluations(22). NHANES was approved by the IRB of the National Center for Health Sciences of the US CDC. All participants gave informed consent.

\section{Definitions of variables}

Questionnaires were used to obtain sociodemographic, respiratory disease, comorbidity, modified poverty index ratio (PIR), and smoking history data. A participant was considered to have 'current asthma' if he/she responded affirmatively to both questions: "Has a doctor or other health professional ever told you that you have asthma?", and "In the past 12 months have you had wheezing or whistling in your chest?". Body mass index (BMI) was categorized as: $<20$ (underweight), 20 to $<25$ (normal weight), 25 to $<30$ (overweight), and $\geq 30$ (obese), accounting for age. Modified PIR was used as a socioeconomic status measure, defined as a family income to poverty threshold ratio (from the Health and Human Services Department guidelines; $\geq 1$, 'high income'). Smoking status was classified as 'never smoked', 'ex-smoker' and 'active smoker' using participants' answers to the questions "Have you smoked at least 100 cigarettes in your entire life?" and "Do you now smoke cigarettes?". A participant was considered to be 'physically active' if he/she answered affirmatively to any question on vigorous or moderate work or recreational activities.

\section{Lung function and fractional exhaled nitric oxide}

Participants had body measurements, spirometry and fractional exhaled nitric oxide (FeNO) acquired at a subsequent visit to a NHANES clinic. Spirometry was based on current American Thoracic Society standards(23), performed using Ohio 822/827 dry-rolling spirometers (Ohio Medical, Gurnee, IL, USA) Technologists required training by NIOSH. FeNO was measured with NIOX MINO ${ }^{\mathrm{TM}}$ monitors following ATS/ERS 2005 recommendations(24).

\section{Blood eosinophils and serum testosterone}

Peripheral blood was collected from participants aged 6+ years during the NHANES clinic visit, from which eosinophil counts and serum testosterone were determined. Absolute eosinophil counts were analyzed using Beckman Coulter method on Coulter® HMX hematology analyzers. Serum testosterone was measured through isotope dilution liquid chromatography/tandem mass spectrometry using NIST methods(25).

\section{Definition of type 2 inflammation}

Type 2 inflammation was assessed by blood eosinophils and FeNO, with high levels defined as 300+ eosinophils/uL and 25+ parts per billion (ppb), respectively. Effect modification for 
associations between testosterone and current asthma by type 2 inflammation markers was tested with interaction terms.

\section{Statistical analysis}

Statistical analyses were performed with SAS 9.4 software (SAS Institute, Cary, NC, USA). Sampling units for each variable were used to account for the survey design complexity representative of the larger U.S. population. Weighted means and standard deviations (SDs) were used to describe continuous variables. Weighted frequency and percentages were used for categorical variables. Univariate analysis using Pearson's chi-square test assessed differences among participants with and without current asthma.

Serum testosterone was analyzed using continuous (ng/dL), log-transformed, and ordinal data. Regression analyses were sex-stratified considering biological differences in sex hormones across sexes. Weighted logistic regression examined the relationship between serum testosterone and binary "current asthma." Weighted regression examined the association between serum testosterone and spirometric readouts. Multivariate models were adjusted for age, race/ethnicity, PIR, BMI, physical activity, and smoking status. The following models were constructed to evaluate covariates effects on "current asthma": age, race/ethnicity, PIR, BMI (model A), model A plus physical activity (model B) and model A plus smoking status (model C). Since models B and C showed similar findings as model A, model A was used throughout, prioritizing parsimony (fewest covariates that do not substantially change results). Missing data was handled by listwise deletion. Since missing observations in serum testosterone exceeded $10 \%$, multiple imputation was performed to confirm similarity of estimates, using hot-deck imputation. P-values $<0.05$ were considered statistically significant.

\section{Results}

Data on current asthma status were available for 7,584 participants from NHANES 20112012 (Table 1). Consistent with contemporary estimates, 601 participants $(7.9 \%)$ had current asthma, 450 of whom ( 215 males and 235 females) had serum testosterone measured. Those with current asthma, relative to those without, were younger ( 34 vs 37 years, $\mathrm{p}<0.01$ ), more likely Black (37 vs 27\%, p <0.01) and with a PIR<1 (37 vs 29\%, p=0.02). Currently asthmatic participants were more likely overweight or obese (52 vs 46\%, p<0.01) and current or former smokers (53 vs 40\%, p<0.01). Those with current asthma had a lower mean pre-bronchodilator forced expiratory volume in the first second of expiration $\left(\mathbf{F E V}_{\mathbf{1}}\right)$ ( 2.8 vs $3.2 \mathrm{~L}, \mathrm{p}<0.01)$, a higher mean FeNO ( 25 vs $15 \mathrm{ppb}, \mathrm{p}<0.01)$ and higher peripheral blood eosinophil counts (302 vs 190 cells $/ \mu \mathrm{L}, \mathrm{p}<0.01)$ than those without current asthma. The mean serum testosterone level was statistically significantly lower among those with current asthma compared to those without (148 vs $201 \mathrm{ng} / \mathrm{dL}, \mathrm{p}<0.01$ ). Log-transformed serum testosterone showed a bimodal distribution due to sex differences in testosterone. Mean testosterone levels were higher in men ( 347 vs. $23 \mathrm{ng} / \mathrm{dL}$, respectively) (Supplementary table 1, Supplementary figure 1).

We found that serum testosterone inversely associates with current asthma prevalence in both sexes after adjustment by age, race/ethnicity, PIR, and BMI (Supplementary table 2). 
Considering we had missing data, we corroborated these results and found similar point estimates and confidence intervals through multiple imputation (Supplementary table 3). Inspection of these results suggested a non-linear association between testosterone and current asthma. We addressed non-linearity by repeating our analyses through $\log _{2^{-}}$ transformation of continuous testosterone data. For every 1-unit increase in $\log _{2}$ testosterone, the odds of current asthma decreased by $11 \%$ (95\%CI 3-19\%, $\mathrm{p}=0.01$ ) in men, after adjustment by age, race/ethnicity, PIR, and BMI (Table 2). The point estimate was similar in women (10\% decrease in the odds of current asthma) but not statistically significant (95\% CI - 4 to $21 \%$ decrease, $\mathrm{p}=0.14$ ). We corroborated these results through multiple imputation (Supplementary table 4). To further clarify the relationship between testosterone and current asthma for both sexes, we analyzed serum testosterone as an ordinal variable. We found that the point estimate for odds of current asthma for the middle and highest tertile in serum testosterone was similar in men, while in women, only the highest tertile showed a similar inverse association with current asthma, although not statistically significant (Table 3). We further delineated the range of serum testosterone that exhibit inverse associations with current asthma in women by dividing the data into smaller percentiles (deciles), and found that only the top decile (range 40-379ng/dL) exhibited a non-statistically significant inverse association with current asthma (Supplementary table 5). These findings suggest that serum testosterone inversely and non-linearly associates with current asthma regardless of sex, but that differences in this inverse relationship may exist between sexes.

As with sex, testosterone also varies by age, with post-pubertal individuals typically having greater testosterone levels (mean serum testosterone levels for ages $<12$ and $\geq 12$ years were 11 and $213 \mathrm{ng} / \mathrm{dL}$, respectively) (Supplementary table 6). We therefore examined whether the association between $\log _{2}$-transformed testosterone and asthma persists before and after puberty, for which we used age 12 years as a defining (and arbitrary) cutoff (Table 4 ). Among male participants aged $12+$ years, for every 1 -unit increase in $\log _{2}$ testosterone the odds of current asthma decreased by $28 \%(\mathrm{n}=2,170,95 \% \mathrm{CI} 19-37 \%$, $\mathrm{p}<0.01)$, after adjustments. The point estimate also suggested a protective effect for females aged $12+$ years but the association was not statistically significant. However, the association between $\log _{2}$-transformed serum testosterone and current asthma prevalence among females age $12+$ was protective and statistically significant when applying multiple imputation (Supplementary table 7), which also confirmed other non-imputed results. No significant association was seen in participants $<12$ years old ( $n=735$, non-imputed; $n=2,103$, imputed).

We sought to understand the association between type 2 inflammation (using blood eosinophils and FeNO as markers), serum testosterone and current asthma. We found that for every 1-unit increase in $\log _{2}$-transformed serum testosterone there is 0.13 unit increase in log-transformed FeNO (95\% CI 0.10-0.16, p=<0.01) (Supplementary table 8). Logtransformed eosinophils did not associate with $\log _{2}$-transformed serum testosterone. Further, we did not find evidence of effect modification on the association between testosterone and current asthma by type 2 inflammatory markers, as neither interaction term achieved statistical significance. Further, although point estimates had the same directionality as the above unstratified analyses, associations between testosterone and current asthma were not statistically significant in FeNO- and eosinophil-stratified analyses. 
Having characterized the association between serum testosterone level and current asthma prevalence, we then sought to determine if testosterone level related to lung function among currently asthmatic participants (Table 5). In men, we found that for every 1-unit increase in $\log _{2}$ testosterone there was a $268.3 \mathrm{~mL}$ increase in $\mathrm{FEV}_{1}(\mathrm{n}=151,95 \%$ CI $203.8-332.7 \mathrm{~mL}$, $\mathrm{p}<0.01), 352.1 \mathrm{~mL}$ increase in $\mathrm{FEV}_{1}$ in women $(\mathrm{n}=161,95 \% \mathrm{CI} 188.7-515.5 \mathrm{~mL}, \mathrm{p}<0.01)$. We corroborated our findings through multiple imputation (Supplementary table 9). Finally, we found that the serum testosterone-FEV ${ }_{1}$ correlation was slightly larger among female participants with current asthma compared to female participants without $(352.1 \mathrm{vs.} 251 \mathrm{~mL}$, respectively; $\mathrm{n}=1,788,95 \% \mathrm{CI} 228.5-274.7 \mathrm{~mL}, \mathrm{p}<0.01$ ), and smaller among male participants with current asthma compared to male participants without ( 268.3 vs. $362.2 \mathrm{~mL}$, respectively; $\mathrm{n}=1,903,95 \%$ CI $342.6-381.7 \mathrm{~mL}, \mathrm{p}<0.01$ ).

\section{Discussion}

Using a large, nationally-representative dataset, we found that serum testosterone inversely and non-linearly associated with current asthma prevalence in both sexes. This association seems to be present only post-puberty and does not seem to vary by type 2 inflammatory status. Lastly, our analysis demonstrates that increased serum testosterone levels associate with better lung function among asthmatic participants demographically representative of the American population.

Prior evidence supports the inverse association between androgens and asthma. DeBoer et al recently reported that pubertal increases in the androgen dehydroepiandrosterone sulfate associate with improved lung function and asthma symptoms (based on NHLBI Severe Asthma Research Program data)(21). Previously, Mohan et al documented positive correlations between serum testosterone and lung function in community-dwelling Australian men(20). Our results complement these studies in several important ways. First, serum testosterone inversely associates not only with asthma symptoms but with the diagnosis of asthma per se, which may suggest a role for androgens in decreasing asthma incidence (supported by coincidental decreases in asthma incidence in adult males relative to females)(26). Second, our results suggest that the association between serum testosterone and current asthma prevalence exists not only in teenagers but also in adults. Thus, by considering broad age ranges our analyses suggest that this association is not relevant only to the dramatic hormonal changes of adolescence, but likely that the association is concentration-dependent across the lifespan. Third, serum testosterone associates with decreased current asthma prevalence in both sexes despite widely different ranges. Fourth, we did not find evidence of differences in the testosterone-asthma association by type 2 inflammation status. Finally, our results suggest that serum testosterone non-linearly associates with better lung function in asthmatic relative to non-asthmatic women.

Some findings require clarification. One is the strength of the inverse association in women vs. men between untransformed serum testosterone and current asthma prevalence (31\% vs. $3 \%$ decreased odds of current asthma per $25 \mathrm{ng} / \mathrm{mL}$ increase in serum testosterone, respectively; Supplementary table 2). We caution against concluding that these results imply stronger associations in women. First, these results suggested a non-linear association between serum testosterone and current asthma prevalence and called for our analyses to be 
done using $\log _{2}$-transformed data. Second, this difference in the strength of association by sex using untransformed data relates to the proportion occupied by 25 -unit increments within the range of serum testosterone in men $(0.25-2,544 \mathrm{ng} / \mathrm{mL}) \mathrm{vs}$. in women $(0.25-$ $379 \mathrm{ng} / \mathrm{mL}$ ) being $\sim 1 \%$ vs. $\sim 7 \%$ of the max testosterone value, respectively. In fact, changing testosterone-unit increments to 3.8 units (i.e. $1 \%$ of the max testosterone value in women, $379 \mathrm{ng} / \mathrm{mL}$ ) then point estimates for odds of current asthma become similar to those in men (data not shown). Further, serum testosterone displays a right-skewed distribution in both sexes, but with extreme values seemingly distributed differently across sexes (Supplementary figure 1), which likely affects the testosterone-current asthma association.

Our results using $\log _{2}$-transformed testosterone data also validate the non-linearity detected in our findings using untransformed testosterone data, especially among men, although a protective effect may also be present for women considering supportive results especially among those age $12+$ years (Supplementary table 7). We suspect that values above a threshold concentration in serum testosterone drive the inverse association with current asthma, which may account for the variation in our results according to sex and age strata. Indeed, in sex-stratified analyses it is only the highest tertile in women that showed point estimates for decreased odds of current asthma (Table 3). In contrast, the middle and highest testosterone tertiles in men showed similar point estimates for inverse associations with current asthma. Since the max value in the highest testosterone tertile and decile in women is distributed within the middle tertile in men (Supplementary table 5), it is possible that the threshold for an inverse association with asthma lies somewhere within the highest decile for women, which corresponds to the second decile in men. The idea of a 'protective threshold' may explain the lack of an association between serum testosterone and current asthma in children, since few individuals $<12$ years old exhibit testosterone values above this threshold. Limitations in sample size prevented us from more precisely estimating such threshold. Further, we caution that the large missingness ( $65 \%)$ of testosterone data for participants younger than 12 years limits the accuracy of our multiple imputation results and may underlie the lack of a statistically significant result in this population.

We also found that serum testosterone inversely associates with current asthma regardless of type 2 inflammatory marker levels. We examined the relationship between testosterone and type 2 inflammatory markers based on in vitro and in vivo studies showing that androgens attenuate type 2 airway inflammation(16-18). In this study, we found that greater testosterone levels associated with an increase in FeNO levels but not blood eosinophil counts (Supplementary table 8), which may reflect tissue-dependent differences in biomarker readout (FeNO is collected from the airway, eosinophils are collected from peripheral blood). We tested whether FeNO and eosinophil levels would modify the testosterone-asthma association through interaction terms, and found these not to be significant. We should caution that the lack of statistical significance with interaction terms often results from insufficient statistical power. Indeed, we found that even though point estimates showed the same directionality as the above unstratified analyses, those stratified by type 2 inflammatory markers were not statistically significant-another potential sign of lack statistical power. Considering these limitations, and the complex relationship between androgens and inflammation subtypes, we cannot conclude based on our study results that 
the mechanism by which androgens may mitigate asthma is unlinked to type 2 inflammation.

Similar to the results of Mohan et al(19), we have found a positive correlation between serum testosterone and lung function. Our results expand on theirs by reporting this correlation among asthmatic participants. Our results are also derived from the more diverse American population. We found that the correlation between $\log _{2}$-transformed serum testosterone and $\mathrm{FEV}_{1}$ was slightly larger in female participants with vs. those without asthma (352.1 vs. $251 \mathrm{~mL}$, respectively), but slightly smaller in male participants with vs. those without asthma (268.3 vs. $362.2 \mathrm{~mL}$, respectively). However, differences in samples size may account for these sex-dependent differences between asthmatic and non-asthmatic participants ( $n=312$ vs. $n=3,691$, respectively) as supported by the difference in the width of the confidence intervals $(95 \% \mathrm{CI} 203.8-332.7 \mathrm{~mL}$ vs. $342.6-381.7 \mathrm{~mL}$ for men, $188.7-$ $515.5 \mathrm{~mL}$ vs. $228.5-274.7 \mathrm{~mL}$ for women). Further, the magnitude of these differences is of questionable clinical significance.

This study has several limitations. First, this NHANES dataset only had information available for serum testosterone and not other sex hormones. Indeed, in vitro and in vivo studies demonstrate that the relationship between sex hormones and asthma is complex, complicated by tissue-dependent variations in sex hormone receptor subtype expression(27). However, although not statistically significant likely due to sample size limitations, point estimates suggest that the inverse testosterone-asthma relationship persists among individuals older than 50 years, which we used to define menopause and sex hormone waning (data not shown). We also did not find evidence that oral contraceptive (exogenous sex hormones) use modified the testosterone-asthma association (interaction term was not significant, data not shown). These data suggest that serum testosterone inversely associates with asthma regardless of variations in other sex hormones. Future studies should account for other sex hormones. Second, NHANES is a cross-sectional study therefore temporal and causative relationships cannot be established. Future longitudinal studies with serial serum testosterone measurements should address temporality. However, the interventional trial by Wenzel et al documented asthma symptom and lung function improvements among moderate-severe asthmatic participants to whom inhaled androgens were administered(19). These results suggest that androgens may have a causal role in ameliorating asthma symptoms. We speculate that low serum testosterone (levels lower than the highest decile in women) may serve as a predictive response biomarker to inhaled androgen therapies, but this hypothesis needs confirmation. Third, our definition of "current asthma" relied on participant self-report. However, one would expect misclassification errors with the current asthma diagnosis to bias our results to the null. Fourth, serum testosterone data were only available on $75 \%$ of participants, with smaller subsets when considering covariates. However, our results were corroborated through multiple imputation for missing data. Finally, the relationship between sex hormones and asthma may be better explained by local tissue sex hormone levels rather than systemic ones(28). However, one would expect that if local tissue hormone levels dominated the relationship with asthmatic phenotypes that any relationship with systemic (serum) testosterone levels would be biased towards the null. Our results suggest the contrary, and that simple serum assays provide useful information about 
testosterone-asthma association. Future studies may clarify the interplay between local and systemic androgen levels and asthmatic phenotypes.

In summary, we have found in a nationally-representative cohort that serum testosterone inversely associates with current asthma prevalence, and with better lung function among asthmatic patients, regardless of sex. Prospective studies are needed to determine whether a threshold exists that could identify subgroups at higher risk of having asthma symptoms and for whom androgen therapy may be beneficial.

\title{
Supplementary Material
}

Refer to Web version on PubMed Central for supplementary material.

\section{Sources of funding:}

This work was conducted with the support of grants K23AI125785 to JCC and R01HL116849 to TBC, by generous contributions by the James A. Haley Veterans' Affairs Hospital in Tampa to ABB and KVS, and by the Culverhouse family fund to all authors.

\author{
Abbreviations \\ BMI body mass index \\ FeNO fractional exhaled nitric oxide \\ $\mathbf{F E V}_{1} \quad$ forced expiratory volume in the first second of expiration \\ FVC forced vital capacity \\ ILC2 type 2 innate lymphoid cells \\ NHANES National Health and Nutrition Examination Survey \\ PIR poverty index ratio \\ PPB parts per billion
}

\section{References:}

1. The ENFUMOSA cross-sectional European multicentre study of the clinical phenotype of chronic severe asthma. European Network for Understanding Mechanisms of Severe Asthma. Eur Respir J. 2003;22(3):470-7. [PubMed: 14516137]

2. Leynaert B, Sunyer J, Garcia-Esteban R, Svanes C, Jarvis D, Cerveri I, et al. Gender differences in prevalence, diagnosis and incidence of allergic and non-allergic asthma: a population-based cohort. Thorax. 2012;67(7):625-31. [PubMed: 22334535]

3. Schatz M, Camargo CA Jr. The relationship of sex to asthma prevalence, health care utilization, and medications in a large managed care organization. Ann Allergy Asthma Immunol. 2003;91(6):5538. [PubMed: 14700439]

4. Zein JG, Erzurum SC. Asthma is Different in Women. Curr Allergy Asthma Rep. 2015;15(6):28. [PubMed: 26141573]

5. Kynyk JA, Mastronarde JG, McCallister JW. Asthma, the sex difference. Curr Opin Pulm Med. 2011;17(1):6-11. [PubMed: 21045697] 
6. Zahran HS, Bailey CM, Damon SA, Garbe PL, Breysse PN. Vital Signs: Asthma in Children United States, 2001-2016. MMWR Morb Mortal Wkly Rep. 2018;67(5):149-55. [PubMed: 29420459]

7. Chen Y, Stewart P, Johansen H, McRae L, Taylor G. Sex difference in hospitalization due to asthma in relation to age. J Clin Epidemiol. 2003;56(2):180-7. [PubMed: 12654413]

8. Hyndman SJ, Williams DR, Merrill SL, Lipscombe JM, Palmer CR. Rates of admission to hospital for asthma. BMJ. 1994;308(6944):1596-600. [PubMed: 8025425]

9. Moorman JE, Zahran H, Truman BI, Molla MT, Centers for Disease C, Prevention. Current asthma prevalence - United States, 2006-2008. MMWR Suppl. 2011;60(1):84-6. [PubMed: 21430629]

10. Skobeloff EM, Spivey WH, St Clair SS, Schoffstall JM. The influence of age and sex on asthma admissions. JAMA. 1992;268(24):3437-40. [PubMed: 1460733]

11. Troisi RJ, Speizer FE, Willett WC, Trichopoulos D, Rosner B. Menopause, postmenopausal estrogen preparations, and the risk of adult-onset asthma. A prospective cohort study. Am J Respir Crit Care Med. 1995;152(4 Pt 1):1183-8. [PubMed: 7551368]

12. Zein JG, Dweik RA, Comhair SA, Bleecker ER, Moore WC, Peters SP, et al. Asthma Is More Severe in Older Adults. PLoS One. 2015;10(7):e0133490. [PubMed: 26200463]

13. Kaufman JM, Lapauw B, Mahmoud A, T'Sjoen G, Huhtaniemi IT. Aging and the Male Reproductive System. Endocr Rev. 2019;40(4):906-72. [PubMed: 30888401]

14. Montano LM, Espinoza J, Flores-Soto E, Chavez J, Perusquia M. Androgens are bronchoactive drugs that act by relaxing airway smooth muscle and preventing bronchospasm. J Endocrinol. 2014;222(1):1-13. [PubMed: 24781253]

15. Xu L, Xiang X, Ji X, Wang W, Luo M, Luo S, et al. Effects and mechanism of dehydroepiandrosterone on epithelial-mesenchymal transition in bronchial epithelial cells. Exp Lung Res. 2014;40(5):211-21. [PubMed: 24784499]

16. Cephus JY, Stier MT, Fuseini H, Yung JA, Toki S, Bloodworth MH, et al. Testosterone Attenuates Group 2 Innate Lymphoid Cell-Mediated Airway Inflammation. Cell Rep. 2017;21(9):2487-99. [PubMed: 29186686]

17. Laffont S, Blanquart E, Savignac M, Cenac C, Laverny G, Metzger D, et al. Androgen signaling negatively controls group 2 innate lymphoid cells. J Exp Med. 2017;214(6):1581-92. [PubMed: 28484078]

18. Becerra-Diaz M, Strickland AB, Keselman A, Heller NM. Androgen and Androgen Receptor as Enhancers of M2 Macrophage Polarization in Allergic Lung Inflammation. J Immunol. 2018;201(10):2923-33. [PubMed: 30305328]

19. Wenzel SE, Robinson CB, Leonard JM, Panettieri RA. Nebulized dehydroepiandrosterone-3sulfate improves asthma control in the moderate-to-severe asthma results of a 6-week, randomized, double-blind, placebo-controlled study. Allergy Asthma Proc. 2010;31(6):461-+. [PubMed: 21708057]

20. Mohan SS, Knuiman MW, Divitini ML, James AL, Musk AW, Handelsman DJ, et al. Higher serum testosterone and dihydrotestosterone, but not oestradiol, are independently associated with favourable indices of lung function in community-dwelling men. Clin Endocrinol (Oxf). 2015;83(2):268-76. [PubMed: 25660119]

21. DeBoer MD, Phillips BR, Mauger DT, Zein J, Erzurum SC, Fitzpatrick AM, et al. Effects of endogenous sex hormones on lung function and symptom control in adolescents with asthma. BMC Pulm Med. 2018;18(1):58. [PubMed: 29631584]

22. National Health and Nutrition Examination Survey. About the National Health and Nutrition Examination Survey 2017 [Available from: www.cdc.gov/nchs/nhanes/about_nhanes.htm.

23. Miller MR, Hankinson J, Brusasco V, Burgos F, Casaburi R, Coates A, et al. Standardisation of spirometry. Eur Respir J. 2005;26(2):319-38. [PubMed: 16055882]

24. American Thoracic S, European Respiratory S. ATS/ERS recommendations for standardized procedures for the online and offline measurement of exhaled lower respiratory nitric oxide and nasal nitric oxide, 2005. Am J Respir Crit Care Med. 2005;171(8):912-30. [PubMed: 15817806]

25. Centers for Disease Control and Prevention NHaNES. Laboratory Procedure Manual: Total Testosterone. 2014. 
26. Winer RA, Qin X, Harrington T, Moorman J, Zahran H. Asthma incidence among children and adults: findings from the Behavioral Risk Factor Surveillance system asthma call-back survey-United States, 2006-2008. J Asthma. 2012;49(1):16-22. [PubMed: 22236442]

27. Townsend EA, Sathish V, Thompson MA, Pabelick CM, Prakash YS. Estrogen effects on human airway smooth muscle involve cAMP and protein kinase A. Am J Physiol Lung Cell Mol Physiol. 2012;303(10):L923-8. [PubMed: 23002077]

28. Sathish V, Martin YN, Prakash YS. Sex steroid signaling: implications for lung diseases. Pharmacol Ther. 2015;150:94-108. [PubMed: 25595323] 


\section{Highlights}

What is already known about this topic?

Sex hormones may underlie the sex disparities observed in asthma.

What does this article add to our knowledge?

Serum testosterone inversely associates with current asthma prevalence and correlates with greater lung function in a nationally-representative dataset.

How does this study impact current management guidelines?

Androgen therapy should be further evaluated in asthma. 
Table 1.

Participant characteristics by current asthma status

\begin{tabular}{|c|c|c|c|}
\hline \multirow{2}{*}{ Characteristic } & \multicolumn{2}{|c|}{ Current asthma } & \multirow[t]{2}{*}{ p-value } \\
\hline & Yes & No & \\
\hline Participants, $n$ & 601 & 6,983 & \\
\hline Age, years mean (SD) & $34(21.8)$ & $37(22.2)$ & $<0.01$ \\
\hline Males, $n(\%)$ & $298(49.4)$ & $3,478(45.1)$ & 0.22 \\
\hline Race/ethnicity (\%) & & & $<0.01$ \\
\hline Black & $222(36.9)$ & $1,852(26.5)$ & \\
\hline White & $187(31.1)$ & $2,045(29.4)$ & \\
\hline Hispanic & $111(18.5)$ & $1,795(25.7)$ & \\
\hline Asian & $48(8)$ & $1,037(14.9)$ & \\
\hline Other & $33(5.5)$ & $254(3.6)$ & \\
\hline PIR $<1$ & $201(36.6)$ & $1,821(28.6)$ & 0.02 \\
\hline Overweight or obese (\%) & $298(51.6)$ & $3,040(45.3)$ & $<0.01$ \\
\hline Current or former smoker (age $\geq 20$ years) & $171(52.9)$ & $1,642(39.7)$ & $<0.01$ \\
\hline Pre-bronchodilator $\mathrm{FEV}_{1}$ (L) & $2.8(2.7-3)$ & $3.2(3.1-3.2)$ & $<0.01$ \\
\hline FeNO mean $\left(\right.$ ppb) $(\mathrm{SD})^{\S}$ & $24.5(27.3)$ & $15.4(12.4)$ & $<0.01$ \\
\hline Eosinophil count $($ cells $/ \mu \mathrm{L}))^{q I}(\mathrm{SD})$ & $302.2(267.6)$ & $190.4(154)$ & $<0.01$ \\
\hline Serum testosterone level $(\mathrm{ng} / \mathrm{dL})^{\frac{F^{t}}{t^{6}}}(\mathrm{SD})$ & $147.8(201.3)$ & $200.6(228.8)$ & $<0.01$ \\
\hline
\end{tabular}

Data are presented as \% unless otherwise stated. FeNO: fractional exhaled nitric oxide; FEV1: forced expiratory volume in 1 second; n: number of participants; PIR: poverty index ratio; PPB: parts per billion; SD: standard deviation.

Sample sizes for each participant characteristic, divided by current asthma status:

$\xi_{\mathrm{n}(\text { with current asthma) }}=423, \mathrm{n}$ (without current asthma) $=5,070$;

$\mathbb{I}_{\mathrm{n}(\text { with current asthma })}=535, \mathrm{n}($ without current asthma $)=6,158 ;$

${ }_{\mathrm{n}}($ with current asthma $)=450, \mathrm{n}($ without current asthma $)=5,262$.

- In this study, all analyses on the relationship between testosterone and asthma assumed Model A adjustments (which included age, sex, race/ ethnicity, PIR, and BMI as covariates) and had a sample size $=5,009$ (current asthma: 409; without current asthma $=4,600$ ). 
Table 2.

Association between $\log _{2}$-transformed serum testosterone level and current asthma, stratified by sex

\begin{tabular}{lcc} 
Measure of testosterone & \multicolumn{2}{c}{ Current asthma } \\
& Crude OR (95\% CI) & Adjusted OR (95\% CI) \\
\hline Males (n=2,530) & $\mathbf{0 . 8 6}$ & $\mathbf{0 . 8 9}$ \\
$\quad$ For each 1-unit change in $\log _{2}$ & $\mathbf{( 0 . 8 0 - 0 . 9 2 )}$ & $\mathbf{( 0 . 8 1 - 0 . 9 7 )}$ \\
serum testosterone & $<\mathbf{0 . 0 1}$ & $\mathbf{0 . 0 1}$ \\
p-value & & \\
Females (n=2,479) & 0.97 & 0.90 \\
For each 1-unit change in $\log _{2}$ & $(0.84-1.13)$ & $(0.79-1.04)$ \\
serum testosterone & 0.67 & 0.14 \\
p-value & &
\end{tabular}

Adjusted for age, race/ethnicity, poverty index ratio, and body mass index. Bolded values are statistically significant; 95\% CI appear in parentheses. OR: odds ratio; $\mathrm{n}=5,009$ 
Table 3.

Association between serum testosterone level and current asthma, stratified by sex

\begin{tabular}{|c|c|c|}
\hline \multirow{2}{*}{ Measure of testosterone } & \multicolumn{2}{|c|}{ Current asthma } \\
\hline & Crude OR (95\% CI) & Adjusted OR (95\% CI) \\
\hline \multicolumn{3}{|c|}{ Males: Tertiles (n, range in ng/dL) } \\
\hline $1^{\mathrm{st}}(858,0.25-262.00)$ & 1 (reference) & 1 (reference) \\
\hline $2^{\text {nd }}(848,262.44-429.29)$ & $0.44(0.28-0.71)$ & $0.49(0.32-0.76)$ \\
\hline $3^{\text {rd }}(824,429.62-2,543.99)$ & $0.44(0.21-0.90)$ & $0.47(0.21-1.04)$ \\
\hline Test for trend $\mathrm{p}$-value & 0.03 & 0.06 \\
\hline \multicolumn{3}{|c|}{ Females: Tertiles (n, range in ng/dL) } \\
\hline $1^{\mathrm{st}}(838,0.25-13.84)$ & 1 (reference) & 1 (reference) \\
\hline $2^{\text {nd }}(822,13.85-24.09)$ & $1.35(0.83-2.19)$ & $1.27(0.77-2.09)$ \\
\hline $3^{\text {rd }}(819,24.13-379.13)$ & $1.05(0.63-1.74)$ & $0.90(0.55-1.48)$ \\
\hline Test for trend $\mathrm{p}$-value & 0.92 & 0.55 \\
\hline
\end{tabular}

Adjusted for age, race/ethnicity, poverty index ratio, and body mass index. Bold odds ratios are statistically significant; $95 \% \mathrm{CI}$ appear in parentheses. OR: odds ratio. $\mathrm{n}=5,009$ 
Table 4.

Association between $\log _{2}$-transformed serum testosterone level and current asthma, stratified by age $<12$ $(\mathrm{n}=735)$ vs. $\geq 12(\mathrm{n}=4,274)$ years, stratified by sex

\begin{tabular}{|c|c|c|}
\hline \multirow{2}{*}{ Measure of testosterone } & \multicolumn{2}{|c|}{ Current asthma } \\
\hline & Crude OR (95\% CI) & Adjusted OR (95\% CI) \\
\hline \multicolumn{3}{|l|}{ Males age $<12$ years $(n=368)$} \\
\hline For each 1-unit change in $\log _{2}$ & 0.81 & 0.85 \\
\hline serum testosterone & $(0.57-1.14)$ & $(0.64-1.14)$ \\
\hline p-value & 0.21 & 0.27 \\
\hline \multicolumn{3}{|l|}{ Females age $<12$ years $(n=367)$} \\
\hline For each 1-unit change in $\log _{2}$ & 0.89 & 0.91 \\
\hline serum testosterone & $(0.61-1.31)$ & $(0.62-1.34)$ \\
\hline p-value & 0.55 & 0.62 \\
\hline \multicolumn{3}{|l|}{ Males age $\geq 12$ years $(n=2,170)$} \\
\hline For each 1-unit change in $\log 2$ & 0.72 & 0.72 \\
\hline serum testosterone & $(0.63-0.83)$ & $(0.63-0.81)$ \\
\hline p-value & $<0.01$ & $<0.01$ \\
\hline \multicolumn{3}{|l|}{ Females age $\geq 12$ years $(n=2,104)$} \\
\hline For each 1-unit change in $\log _{2}$ & 0.94 & 0.90 \\
\hline serum testosterone & $(0.80-1.10)$ & $(0.74-1.05)$ \\
\hline $\mathrm{p}$-value & 0.40 & 0.15 \\
\hline
\end{tabular}

Adjusted for age, race/ethnicity, poverty index ratio, and body mass index. Bolded values are statistically significant; 95\% CI appear in parentheses. OR: odds ratio. 
Table 5.

Association between $\log _{2}$-transformed serum testosterone level and change in $\mathrm{FEV}_{1}(\mathrm{~mL})$ in participants with current asthma, stratified by sex

\begin{tabular}{|c|c|c|}
\hline \multirow{2}{*}{ Measure of testosterone } & \multicolumn{2}{|c|}{ Current asthma } \\
\hline & Crude change in $\mathrm{FEV}_{1}$ in $\mathrm{mL}(95 \% \mathrm{CI})$ & Adjusted change in $\mathrm{FEV}_{1}$ in $\mathrm{mL}(95 \% \mathrm{CI})$ \\
\hline \multicolumn{3}{|l|}{ Males $(n=151)$} \\
\hline For every 1-unit change in $\log _{2}$ & 226.1 & 268.3 \\
\hline serum testosterone & (173.2-279.0) & (203.8-332.7) \\
\hline p-value & $<0.01$ & $<0.01$ \\
\hline \multicolumn{3}{|l|}{ Females $(n=161)$} \\
\hline For every 1-unit change in $\log _{2}$ & 329.0 & 352.1 \\
\hline serum testosterone & (186.6-471.3) & (188.7-515.5) \\
\hline p-value & $<0.01$ & $<0.01$ \\
\hline
\end{tabular}

Adjusted for age, race/ethnicity, poverty index ratio, and body mass index. Bolded values are statistically significant; 95\% CI appear in parentheses. $\mathrm{FEV}_{1}$ : forced expiratory volume in the first second of expiration. $\mathrm{n}=312$ includes only those participants with current asthma, available spirometric measurements and complete data on all of the above covariates. 